\title{
Vulval Edema as a Manifestation of Childhood Metastatic Crohn's Disease
}

\author{
Sunil V. Kapur ${ }^{1} \cdot$ Jitendra S. Oswal ${ }^{1} \cdot$ Vijay Viswanathan $^{1}$ \\ Received: 1 January 2020 / Accepted: 15 June 2020 / Published online: 10 July 2020 \\ (C) Dr. K C Chaudhuri Foundation 2020
}

To the Editor: A 12-y-old female child presented with recurrent aphthous ulcers since the last two years, vulval swelling since the last nine months, abdominal pain since the last one month with significant weight loss. On examination she had multiple painful aphthous ulcers on the lips, failure to thrive, painful asymmetrical bilateral vulval and clitoral edema, and perianal tags. Investigations revealed anemia $(\mathrm{Hb}=8.9 \mathrm{~g} / \mathrm{dl})$, normal $\mathrm{WBC}(\mathrm{WBC}=6200 / \mathrm{cmm} ; N=68 \%, \mathrm{~L}=22 \%)$, raised platelet counts (Platelets $=4.57$ lakhs), raised CRP $(67 \mathrm{mg} / \mathrm{L})$, low albumin $(1.75 \mathrm{~g} / \mathrm{dl})$, and high fecal calprotectin $(310 \mu \mathrm{g} / \mathrm{g})$. Ophthalmology examination was normal. Mantoux and pathergy test were negative. Colonoscopy revealed multiple linear ulcers with skip areas from caecum to sigmoid colon. Colonic biopsy revealed noncaseating granulomas. Though desirable, patient refused vulval biopsy. On the basis of the above clinical, endoscopic and biopsy findings, the diagnosis of "metastatic" vulval and intestinal Crohn's Disease (CD) was made. She was treated with exclusive enteral nutrition therapy with polymeric formula, azathioprine, and steroids with significant improvement of both vulval edema and intestinal CD within four months of therapy with normalization of inflammatory parameters and fecal calprotectin.

"Metastatic" CD is defined by the presence of skin lesions without contiguity with the gastrointestinal tract. Vulval involvement in $\mathrm{CD}$ is extremely rare in children $[1,2]$. Labia majora erythema and edema are common manifestations and in few cases these may progress to ulceration [3]. Perianal lesions have been estimated to be between $13.6 \%$ and $62 \%$ in pediatric CD patients [4]. Studies show that $20 \%-36 \%$ of patients with vulval $\mathrm{CD}$ do not exhibit any gastrointestinal

Jitendra S. Oswal

dmd.bharatihospital@gmail.com

1 Department of Pediatrics, Bharati Vidyapeeth University Medical College Hospital \& Research Centre, Pune 411043, India symptoms, and vulval CD may be the first manifestation of their underlying disease [5]. Simultaneous presence of intestinal CD on colonic biopsy, perianal tags and disappearance of vulval edema to $\mathrm{CD}$ treatment was suggestive that the diagnosis was most likely "metastatic" CD. Recovery of "metastatic" lesions is variable, often refractory, and does not parallel to that of intestinal lesions. Treatment options include corticosteroids (topical, intralesional, systemic), antibiotics, traditional immunosuppressants, biologics and surgical debridement, all of which have shown mixed results. We report this case as vulval involvement of childhood $\mathrm{CD}$ is an under-recognized manifestation.

\section{Compliance with Ethical Standards}

Conflict of Interest None.

\section{References}

1. Das D, Gupta B, Saha M. Metastatic vulvar Crohn's disease - a rare case report and short review of literature. Indian J Dermatol. 2016;61:70-4.

2. Madnani N, Desai D, Gandhi N, Khan K. Isolated Crohn's disease of the vulva. Indian J Dermatol Venereol Leprol. 2011;77:342-4.

3. Reyes M, Borum M. Severe case of genital and perianal cutaneous Crohn's disease. Inflamm Bowel Dis. 2009;15:1125-6.

4. Keljo DJ, Markowitz J, Langton C, et al. Course and treatment of perianal disease in children newly diagnosed with Crohn's disease. Inflamm Bowel Dis. 2008;15:383-7.

5. Abboud ME, Frasure SE. Vulvar inflammation as a manifestation of Crohn's disease. World J Emerg Med. 2017;4:305-7.

Publisher's Note Springer Nature remains neutral with regard to jurisdictional claims in published maps and institutional affiliations. 